\title{
Near-peer teaching in het coschap Interne Geneeskunde: een gerandomiseerde cross-over trial
}

\author{
N. Wlazlo, B. Winkens, C.P.M. van der Vleuten, W.G. Peters
}

\section{Samenvatting}

Inleiding: Uit diverse studies is gebleken dat de toepassing van near-peer teaching in het trainen van medisch technische vaardigheden (skills) en in het tutoriaal probleemgestuurd onderwijs (PGO) gelijkwaardig is aan het door stafleden gegeven onderwijs. Het is echter nog onvoldoende onderzocht of ouderejaars studenten ook als docent van theoretisch, klinisch onderwijs kunnen functioneren. Daarom vergeleken wij in een gerandomiseerde crossover studie de kwaliteit en wenselijkheid van near-peer teaching met regulier onderwijs.

Methode: Zesentwintig vierdejaars studenten geneeskunde kregen wekelijks een uur theoretisch onderwijs in de algemene interne geneeskunde. Dit onderwijs werd beurtelings gegeven door een zesdejaars student (semi-arts) en een staflid (internist-hematoloog). Coassistenten werden willekeurig ingedeeld in een groep die begon met de semi-arts en een groep die begon met de internist. Per student werden vier onderwijsmomenten geëvalueerd aan de hand van een vragenlijst bestaande uit 16 items; de gemiddelde scores van deze items (de totaalbeoordeling) werden vergeleken middels linear mixed models.

Resultaten: In totaal werden 92 vragenlijsten verzameld. De totaalbeoordeling van het onderwijs was significant hoger bij de semi-arts (8.31); de internist scoorde $8.00(p=0.004)$. Uit de scores op de vragenlijst bleek dat er in het onderwijs door de semi-arts sprake was van meer interactiviteit en stimulatie in een plezierige leeromgeving, alsmede meer overzicht en fysiologische uitleg.

Conclusies: Theoretisch onderwijs door een ouderejaars student wordt even hoog gewaardeerd als onderwijs door een staflid. Deze resultaten kunnen verklaard worden door de aanwezigheid van cognitieve en sociale congruentie, of door het feit dat didactische vaardigheden belangrijker zijn dan vakinhoudelijke kennis. (Wlazlo $N$, Winkens B, Vleuten CPM van der, Peters WG. Near-peer teaching in het coschap Interne Geneeskunde: een gerandomiseerde cross-over trial. Tijdschrift voor Medisch Onderwijs 2011;30(1-2):2-10)

\section{Inleiding}

Peer-peer teaching heeft de laatste jaren een steeds grotere rol gekregen in de opleiding Geneeskunde. ${ }^{1-3}$, Een van de gedachtes daarachter is dat het eigen leerproces wordt bevorderd door het onderwijzen van anderen. ${ }^{1}$ Wanneer het onderwijs wordt gegeven door personen die niet in dezelfde sociale groep (c.q. academisch jaar) zitten, zoals ouderejaars studenten die één tot twee jaar ouder zijn, dan spreekt men eigenlijk van near-peer teaching. ${ }^{4-5}$
Naar het geven van near-peer teaching zijn diverse (gecontroleerde) studies gedaan. De meeste hiervan richtten zich op het trainen van medisch technische vaardigheden (skillslab) en zijn uitgevoerd in de eerste jaren van de opleiding. ${ }^{6-13} \mathrm{Bij}$ objectieve toetsing van deze vaardigheden (Objective Structured Clinical Examination; OSCE) werden in vergelijking tot studenten die door stafleden onderwezen werden, gelijke tot hogere resultaten gevonden bij studenten die onderwezen 
werden in een near-peer setting. Bovendien werd dit onderwijs door studenten vaak positiever gewaardeerd.

Ouderejaars studenten en stafleden functioneren even goed als tutor/procesbegeleider in probleemgestuurd onderwijs (PGO). ${ }^{4-14}$ Het is echter onbekend of een (ouderejaars) student ook effectief een rol als docent in het theoretisch onderwijs kan vervullen, en of dergelijk onderwijs van vergelijkbare kwaliteit is als het onderwijs door stafleden. In een studie onder laatstejaars studenten leidde near-peer teaching door eerstejaars artsassistenten tot betere resultaten bij een schriftelijk examen, en in een ander onderzoek werden hogere zelfbeoordelingen gevonden bij studenten die onderwezen werden door ouderejaars studenten. ${ }^{15-16}$ In deze studies was echter geen sprake van een controlegroep met regulier onderwijs zodat er geen vergelijking mogelijk was.

Om de kwaliteit en wenselijkheid van klinisch, theoretisch onderwijs door een ouderejaars te vergelijken met regulier onderwijs door een staflid, voerden wij een gerandomiseerde cross-over studie uit naar het geven van dergelijk onderwijs aan coassistenten door een senior student (semi-arts).

\section{Methode}

\section{Personen en opzet van het onderwijs}

Interne Geneeskunde is een verplicht coschap van tien weken in het vierde jaar van de opleiding Geneeskunde in Maastricht. Studenten volgen vóór en na het coschap een week onderwijs in Maastricht en lopen in de tussenperiode acht weken klinische stage ofwel in het Maastrichts Universitair Medisch Centrum ofwel in een perifeer ziekenhuis, zoals het onze (Catharina Ziekenhuis Eindhoven). Aan alle coassistenten die in de periode september 2009 tot en met mei 2010 een co- schap Interne Geneeskunde volgden in het Catharina Ziekenhuis werd gevraagd in studieverband het gevolgde onderwijs (anoniem) te evalueren (informed consent).

Tijdens deze acht weken stage kregen de coassistenten wekelijks op dinsdag een uur onderwijs in de interne geneeskunde. In een cross-over opzet werden coassistenten beurtelings onderwezen door de coassistentenbegeleider (WP), een ervaren internist-hematoloog, in de eerste en derde week van de maand, en door de semi-arts (NW) in de tweede en vierde week. De coassistenten werden aan het begin van hun coschap willekeurig ingedeeld in een groep die begon met onderwijs door de internist of in een groep die startte met onderwijs door de semi-arts. Elke coassistent werd gevraagd om vier maal achtereenvolgens het gevolgde onderwijs te evalueren (tweemaal bij de arts en tweemaal bij de semi-arts). Zo ontstond er een groep die onderwijs kreeg in de volgorde WP-NW-WP-NW, en een groep met de volgorde NW-WP-NW-WP. Uiteraard waren studenten en tutoren niet geblindeerd. Vanwege het wekelijkse karakter van het onderwijs hadden studenten tussen twee onderwijsmomenten een wash-out-periode van één week, zodat het vorige onderwijs geen invloed had op de beoordeling van het volgende onderwijs.

De grootte van de groep coassistenten aan wie het onderwijs van een uur werd gegeven varieerde van drie tot zes studenten. Tijdens de onderwijsmomenten waren de coassistenten vrij een onderwerp te kiezen voor discussie. Meestal werden de diagnose en de behandeling van de belangrijkste algemene problemen in de interne geneeskunde besproken, zoals anemie, icterus, leverfalen, vocht en elektrolyten, schildklierziekten, nierfunctiestoornissen en hematologische malig- 
niteiten. Rekening houdend met het verloop in coassistenten werden onderwerpen altijd zo gekozen dat studenten nooit twee keer hetzelfde onderwerp meemaakten. Beide tutoren waren vrij in hun wijze van onderwijs en er werd geen gebruik gemaakt van digitale hulpmiddelen.

De internist was sinds 1984 werkzaam in de interne geneeskunde en had 26 jaar ervaring opgebouwd in het geven van onderwijs aan coassistenten. De semi-arts was een zesdejaars student geneeskunde van 23 jaar oud, die het laatste jaar van zijn opleiding doorbracht met een wetenschaps- en gezondheidszorgparticipatie bij de Interne Geneeskunde ('wetenschapsstage' en 'oudste coschap'). Hij bereidde zijn eerste sessies voor met het boek "Harrison's principles of internal medicine", maar kreeg geen specifieke training. Wel dient vermeld te worden dat hij vier jaar ervaring had in het geven van bijlessen aan middelbare scholieren, maar ook in die context had hij nooit enige didactische opleiding of training genoten.

\section{Evaluatie van het onderwijs}

Aan het begin van de studie werd van alle coassistenten de leeftijd en het geslacht vastgelegd. Direct na elk onderwijsmoment werden de volgende data verzameld: tutor (WP/NW), onderwerp van onderwijs, week van het coschap (1-8), evaluatienummer (1-4) en de docent van wie ze de eerste keer onderwijs hadden gekregen (WP/NW). De onderwijssessies werden geëvalueerd aan de hand van een vragenlijst, die ten dele gebaseerd was op de eindtermen voor de lerarenopleiding aan Fontys Hogeschool. In overleg met beide docenten (WP/NW) werden belangrijke aspecten van dit onderwijs opgenomen en bewerkt, en werd de vragenlijst zo generiek geformuleerd dat deze toegepast kon worden op het in deze studie gegeven on- derwijs (zie Figuur 1). De vragenlijst bevatte 16 items aangaande de beoordeling van het onderwijs en de tutor op een tienpunts Likertschaal ( 1 = helemaal mee oneens; 10 = helemaal mee eens) en twee items over het onderwijs als geheel en over het functioneren van de tutor, uit te drukken in een cijfer (1-10). Drie vragen werden invers geformuleerd om respons bias te voorkomen.

\section{Statistische analyse}

De interne consistentie van de vragenlijst was goed (Cronbach's alpha 0.849). Na omrekening van inverse items werden vervolgens de twee eindcijfers voor onderwijs en tutor en de gemiddelde score van de 16 items (vanaf nu totaalbeoordeling genoemd) vergeleken tussen arts en semiarts (waarden uitgedrukt als gemiddelden en standaarddeviaties).

Omdat er sprake was van vier afhankelijke metingen per student (twee bij de internist en twee bij de semi-arts), analyseerden we het 'tutor effect' met een linear mixed model met een random intercept, random tutoreffect of beide. Op grond van het Bayesian Informatie Criterium (BIC) werden modellen onderling vergeleken en werd het beste model gekozen voor de analyse. Het BIC is een maat voor hoe goed het model bij de data past ('goodness-of-fit'), net zoals de likelihood. De BIC corrigeert echter ook voor het aantal parameters in het model, en hoe lager de BIC, hoe beter het model past bij de data. Naast het 'tutoreffect' werd een periodeeffect (evaluatie 1-4) als fixed factor in het model opgenomen. Ook werd getest op een interactie tussen tutor en periode.

Door het randomiseren was het evaluatiemoment geen reflectie van de daadwerkelijke week van het coschap waarin de studenten werkelijk zaten. Daarom vergeleken we in een sensitiviteitsanalyse de verkregen resultaten met een analyse 

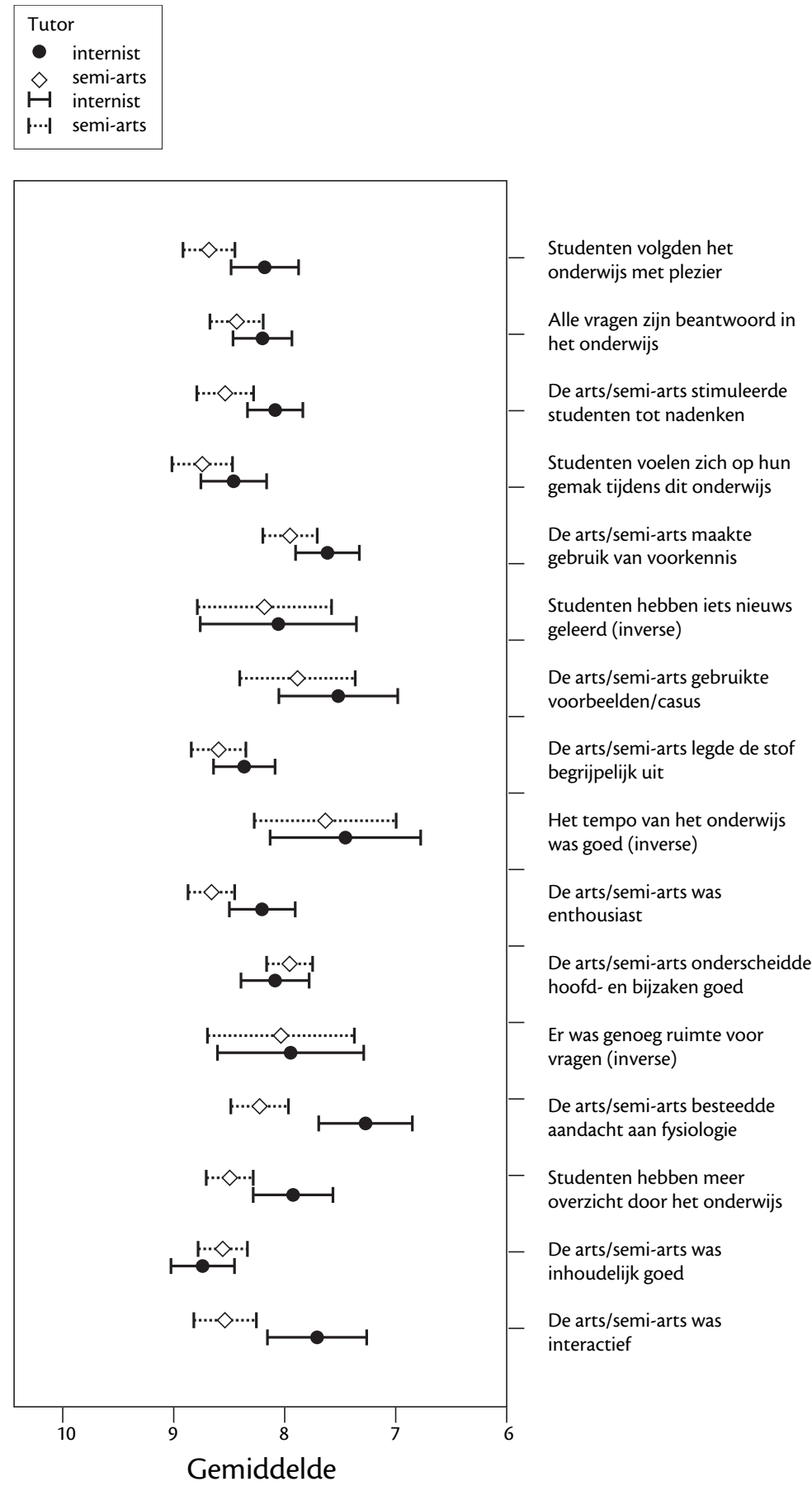

Figuur 1. Ongecorrigeerde gemiddeldes per tutor.*

* De staven geven de $95 \%$ betrouwbaarheidsintervallen weer. 
die niet het evaluatiemoment als periodeeffect gebruikte, maar de week van het coschap (1-8). Een tweezijdige p-waarde van $\leq 0.05$ werd als statistisch significant beschouwd. Alle analyses werden uitgevoerd met Statistical Package for Social Sciences (SPSS) for Windows, version 17.0 (SPSS Inc., Chicago, IL, USA).

\section{Resultaten}

Personen en onderwerpen van onderwijs Gedurende de onderzoeksperiode volgden 26 coassistenten een coschap interne geneeskunde in het Catharina ziekenhuis, die allemaal instemden met participatie in de studie. Achttien studenten waren vrouw $(69 \%)$ en de mediane leeftijd bedroeg 22.3 jaren (interkwartiel afstand 21.9 - 23.5). Twaalf studenten startten met de internist als tutor, en 14 studenten kregen hun eerste onderwijs van de semiarts.

Vanwege ziekte, vakantie of vervallen onderwijsmomenten waren niet alle studenten in staat vier evaluaties in te leveren. Achttien studenten (69\%) evalueerden alle vier de sessies, vier studenten (15\%) evalueerden drie sessies en vier studenten $(15 \%)$ evalueerden slechts twee sessies. Dit leverde in totaal 92 ingevulde vragenlijsten op, waarvan in 43 de internist werd geëvalueerd en in 49 de semi-

Tabel 1. Onderwerpen van onderwijs.

\begin{tabular}{lcc}
\hline & Semi-arts & Internist \\
\hline Cirrose en portale hypertensie & 5 & 0 \\
Nierfunctiestoornissen & 1 & 2 \\
Elektrolyten & 4 & 1 \\
Calciumhuishouding & 1 & 1 \\
Schildklierfunctiestoornissen & 2 & 1 \\
Hematologische maligniteiten & 0 & 4 \\
Veneuze trombo-embolieën & 0 & 2 \\
Anemie & 2 & 1 \\
\end{tabular}

arts. In Tabel 1 staan de onderwerpen die tijdens de sessies door internist en semiarts bediscussieerd werden. Hoewel beide tutoren verscheidene aspecten van de algemene interne geneeskunde bespraken, gaf de internist-hematoloog meer hematologie onderwijs.

\section{Beoordeling van onderwijs en tutor}

Voor de analyse van de eindcijfers voor tutor en onderwijs in het algemeen waren respectievelijk een model met random tutor effect (BIC 206.286) en een model met random intercept (BIC 204.980) het meest geschikt. Voor de totaalbeoordeling werd een model gekozen met random intercept (BIC 197.527), daar toevoeging van een random tutoreffect geen verbetering van het model gaf (BIC 200.918). Het testen op een interactie tussen tutor en periode leverde voor alle drie de uitkomstvariabelen geen significant resultaat op ( $\mathrm{p}$-waarden van respectievelijk $0.505,0.210$ en 0.085 voor eindcijfer tutor, eindcijfer onderwijs en totaalbeoordeling).

In het algemeen ervoeren de coassistenten de onderwijsmomenten als positief, met een gemiddelde totaalbeoordeling van 8.16 (95\% BI $8.01-8.30)$. In Tabel 2 staan de gemiddelde eindcijfers en de totaalbeoordeling gecorrigeerd voor student en periode. Het gemiddelde eindcijfer van de semi-arts als tutor (8.38) was significant hoger dan dat van de internist (7.94; $\mathrm{p}=0.010$ ); ook het onderwijs in het algemeen werd bij de semi-arts hoger gescoord (8.28 versus $7.80 ; \mathrm{p}<0.001$ ). De totaalbeoordeling van het onderwijs, berekend als het gemiddelde van de 16 items op de vragenlijst, was bij de semi-arts significant hoger (8.31); de internist scoorde $8.00(\mathrm{p}=0.004)$. Aangezien het evaluatiemoment niet exact hetzelfde was als de week van het coschap waarin de studenten zich bevonden, werd een sensitiviteits- 
analyse uitgevoerd met de week van het coschap als periode-effect. Voor alle drie de uitkomsten werden hier vergelijkbare resultaten gevonden en dezelfde conclusies getrokken.

Om het verschil in beoordeling te verklaren, zijn in Figuur 1 de ongecorrigeerde gemiddelden van de 16 vragen voor de semi-arts en internist weergegeven. De semi-arts en de internist werden op de meeste items gelijk gewaardeerd. Opvallend was dat de semi-arts meer interactief was, meer overzicht bracht in de materie, meer fysiologie uitlegde, enthousiaster was, en meer stimuleerde tot nadenken, en dat studenten tijdens het onderwijs van de semi-arts meer plezier beleefden.

\section{Discussie}

Onze studie laat zien dat het onderwijs, gegeven door een semi-arts, significant beter gewaardeerd werd dan het onderwijs door een ervaren arts. Uit de vragenlijsten bleek dat dit onder meer toe te schrijven was aan interactiviteit, stimulatie en enthousiasme, overzicht en fysiologie en een veilige leeromgeving. Daar de verschillen in beoordelingen echter klein waren, is het mogelijk beter te spreken van vergelijkbare resultaten voor semiarts en internist. Belangrijk is de constatering dat het resultaat van de semi-arts niet slechter was dan het resultaat van de internist.
Deze resultaten zijn in overeenstemming met andere studies naar near-peer teaching, die geen verschillen in zowel objectieve als subjectieve uitkomstmaten lieten zien tussen groepen die onderwezen werden door 'student teachers' of door professionals. In het merendeel van deze studies is echter onderzoek gedaan naar het geven van vaardigheidstrainingen. ${ }^{6-13}$ Rodrigues et al. lieten zien dat farmacologieonderwijs, gegeven door eerstejaars arts-assistenten aan laatstejaars studenten, tot minder fouten leidde in voorschrijfgedrag bij een examen. ${ }^{15}$ Ook kwam uit vragenlijstenonderzoek naar voren dat tutorgroepen van eerste- en tweedejaars studenten net zo goed door ouderejaars geleid konden worden, en dat deze studenten even goede resultaten behaalden op een toets als studenten met stafleden als tutor. ${ }^{4-14}$ In een studie van Nikendei et al. leidde het geven van tien bedside tutorials interne geneeskunde aan derdejaars studenten door laatstejaars tot hogere zelfbeoordelingen dan enkel het reguliere onderwijs. ${ }^{16}$ In die studie was echter een controlegroep gebruikt, die geen ander aanvullend onderwijs kreeg.

Onze gecontroleerde studie laat zien dat volledig theoretisch onderwijs of klinisch onderwijs goed door een semi-arts gegeven kan worden. Voor deze resultaten kunnen verschillende verklaringen zijn. Ten eerste lijken didactische vaardigheden, zoals interactie, stimulatie, overzicht

Tabel 2. Gemiddelde eindcijfers gecorrigeerd voor student en periode uit linear mixed models.

\begin{tabular}{|c|c|c|c|c|c|c|}
\hline & \multicolumn{2}{|c|}{ Gemiddeldes } & \multirow[t]{2}{*}{ Verschil } & \multicolumn{2}{|c|}{ 95\% BI verschil* } & \multirow[t]{2}{*}{ p-waarde } \\
\hline & Internist & Semi-arts & & & & \\
\hline Eindcijfer tutor & 7.94 & 8.38 & 0.44 & 0.11 & 0.77 & 0.010 \\
\hline Eindcijfer onderwijs & 7.80 & 8.28 & 0.48 & 0.23 & 0.73 & $<0.001$ \\
\hline Totaalbeoordeling & 8.00 & 8.31 & 0.30 & 0.10 & 0.51 & 0.004 \\
\hline
\end{tabular}

* 95\% Bl: $95 \%$ betrouwbaarheidsinterval. 
en enthousiasme, belangrijker dan inhoudelijke kennis of klinische expertise. Verder kan de werkzaamheid van near-peer teaching verklaard worden met cognitieve en sociale congruentie. ${ }^{2} 517$ Het feit dat de semi-arts meer fysiologie behandelde en meer overzicht aanbracht, kan er namelijk ook op wijzen dat deze vakinhoudelijk gezien op hetzelfde niveau als de studenten zit. De ouderejaars student heeft recent zelf de stof bestudeerd die de vierdejaars student nu moet beheersen, en hij weet wat belangrijk is, wat moeilijke onderwerpen zijn en kan hoofd- en bijzaken onderscheiden. ${ }^{2} 5$ Sociale congruentie betekent dat docent en leerling sociaal dichter bij elkaar staan, hetgeen zich in onze studie uitte in een comfortabelere leeromgeving met meer interactie en plezier. In een dergelijke omgeving is de drempel tot het stellen van vragen lager. ${ }^{2} 5$ Tenslotte kan de ouderejaars als rolmodel gezien worden en een stimulans zijn voor het leerproces van de studenten. ${ }^{5} 18$

In studies met near/peer-peer teaching worden professionele docenten door studenten vaak competenter geacht dan de (ouderejaars) studenten, ondanks vergelijkbare objectieve resultaten. ${ }^{4-9}$ In onze studie werden de competentie en de vakinhoudelijke kennis van internist en semi-arts gelijk gewaardeerd. Near-peer teaching is wat dat betreft wellicht wenselijker dan peer-peer teaching, omdat het cognitieve en sociale congruentie bewerkstelligt, maar wel enige professionele afstand tussen docent en leerling in stand houdt.

Onze studie verschilt van de meeste andere studies vanwege het feit dat de semiarts geen specifieke didactische of vakinhoudelijke training had gekregen. ${ }^{4}$ 6-8 10-13 16 Klaarblijkelijk is dit geen harde eis voor near-peer teaching, aangezien de eindbeoordelingen van eenzelfde niveau waren, en in overeenstemming met andere stu- dies waarin de senior peers of ouderejaars ook geen training kregen. ${ }^{9} 15$ Dit komt doordat ouderejaars die in een onderwijsgevende rol geplaatst worden, zelf didactische vaardigheden ontwikkelen. ${ }^{19}$ Door het geven van onderwijs aan coassistenten worden ouderejaars studenten bovendien voorbereid op de onderwijsgevende rol die ze wellicht als arts-assistent moeten gaan vervullen. ${ }^{18-19}$

De zesdejaars student of semi-arts kan dus een goede docent zijn. Desalniettemin staat in dit laatste leerjaar van de opleiding geneeskunde het eigen leerproces ook nog steeds centraal, hetgeen zich kenmerkt door supervisie van het handelen door de begeleiders. Dit eigen leerproces kan gestimuleerd worden door het geven van onderwijs aan coassistenten. In onze studie merkte de semi-arts dat hij na het geven van onderwijs bepaalde onderwerpen beter beheerste. Ook in andere studies gaven de ouderejaars of senior peers aan de stof beter te beheersen na het geven van onderwijs, en daarnaast didactische kwaliteiten ontwikkeld te hebben. 4 6,9-10 13 Het geven van dertig minuten onderwijs leidde bij arts-assistenten tot meer kennis dan het volgen van een dertig minuten durende lezing over hetzelfde onderwerp. ${ }^{20}$ Niet alleen de coassistenten, maar vooral de semi-artsen, kunnen dus baat hebben bij het geven van onderwijs.

Het onderzoek was opgezet als een gerandomiseerde cross-over studie, hetgeen het voordeel had dat veel evaluaties verzameld werden en de 'power' vergroot werd door de herhaalde metingen. Daarbij gebruikten wij een generieke vragenlijst, gebaseerd op de eindtermen voor leraren, waarvan de uitkomsten een betrouwbare weerspiegeling waren van de kwaliteit van het onderwijs. Een nadeel van deze opzet was dat in dit onderzoek slechts één internist en één semi-arts als tutor fungeerden. Logistiek was het echter niet moge- 
lijk om met meer tutoren te werken. Met de extrapolatie van de resultaten van deze studie (en andere) naar semi-artsen in het algemeen dient men dan ook voorzichtig te zijn. ${ }^{4-8} 16$ Daar zesdejaars studenten hun stage in principe lopen bij een vakgebied naar eigen keuze, zouden ze echter wel in staat moeten zijn coassistenten hierover met het zelfde enthousiasme iets bij te brengen als dat van de semi-arts in deze studie.

Daar de onderwijsmomenten alleen met een vragenlijst geëvalueerd werden (Kirkpatrick's niveau 1) en niet met een objectief meetinstrument, zoals een toets of scoringslijst, is het nog onduidelijk of de resultaten van deze studie verklaard kunnen worden door de meerwaarde van didactische vaardigheden ten opzichte van vakinhoudelijke kennis, of door cognitieve en sociale congruentie van de senior student. Aanvullend onderzoek, waarin didactische vaardigheden en congruentie gecorreleerd worden met ervaren leerwaarde en objectieve uitkomstmaten, zoals een kennistoets (Kirkpatrick's niveau 2), is daarvoor nodig. Het doel van deze studie was echter niet om aan te tonen dat onderwijs door semi-artsen het onderwijs van artsen kan vervangen, maar dat het van vergelijkbare kwaliteit is en ook wenselijk. De inzet van beiden levert een goed leerklimaat op voor de coassistenten, brengt de semi-arts vakinhoudelijke kennis en didactische vaardigheden bij en kan de werkdruk van artsen verlichten.

\section{Literatuur}

1. Topping K. The effectiveness of peer teaching in higher and further education: a typology and review of the literature. Higher education 1996;32(3):321-345.

2. Lockspeiser TM, O'Sullivan P, Teherani A, Muller J. Understanding the experience of being taught by peers: the value of social and cognitive congruence. Adv in Health Sci Educ 2008;13:361372.
3. Cate ThJ Ten. Leren in groepen zonder docent. Amsterdam: Universiteit van Amsterdam; 1986. [Learning in groups without teacher. Amsterdam: University of Amsterdam; 1986].

4. Bulte C, Betts A, Garner K, Durning S. Student teaching: views of student near-peer teachers and learners. Med Teach 2007;29:583-590.

5. Cate O ten, Durning S. Dimensions and psychology of peer teaching in medical education. Med Educ 2007;29:546-552

6. Hudson JN, Tonkin AL. Clinical skills education of relationships between junior medical students, senior peers and simulated patients. Med educ 2008;42:901-908.

7. Weyrich P, Celebi N, Schrauth M, Möltner A, Lammerding-Köppel M, Nikendei C. Peer-assisted versus faculty staff-led skills laboratory training: a randomised controlled trial. Med Educ 2009;43:113-120.

8. Heckmann JG, Dütsch M, Rauch C, Lang C, Weih M, Schwab S. Effects of peer-assisted training during the neurology clerkship: a randomized controlled study. Eur J Neurol 2008;15:1365-1370.

9. Knobe M, Münker R, Sellei RM, Holschen M, Mooij SC, Schmidt-Rohlfing B et al. Peer teaching: a randomised controlled trial using student-teachers to teach musculoskeletal ultrasound. Med Educ 2010;44:148-155.

10. Field M, Burke JM, McAllister D, Lloyd DM. Peerassisted learning: a novel approach to clinical skills learning for medical students. Med Educ 2007;41:411-418.

11. Perkins GD, Hulme J, Bion JF. Peer-led resuscitation training for healthcare students: a randomised controlled study. Intensive Care Med 2002;28:698-700.

12. Tolsgaard MG, Gustafsson A, Rasmussen MB, Høiby P, Müller CG, Ringsted C. Student teachers can be as good as associate professors in teaching clinical skills. Med Teach 2007;29:553-557.

13. Weyrich P, Schrauth M, Kraus B, Habermehl D, Netzhammer N, Zipfel S et al. Undergraduate technical skills training guided by student tutors. Analysis of tutors' attitudes, tutees' acceptance and learning progress in an innovative teaching model. BMC Med Educ 2008;8:18.

14. Volder ML de, Grave WS de, Gijselaers W. Peer teaching: academic achievement of teacher-led versus student-led discussion groups. Higher Education 1985;14:643-650.

15. Rodrigues J, Sengupta A, Mitchell A, Kane C, Kane C, Maxwell S et al. The South-east Scotland foundation doctor teaching programme - Is "near-peer" teaching feasible, efficacious and sustainable on a regional scale? Med Teach 2009;31:e51-e57.

16. Nikendei C, Andreesen S, Hoffmann K, Jünger J. Cross-year peer tutoring on internal medicine wards: effects on self-assessed clinical competen- 
cies - A group control design study. Med Teach 2009;31:e32-e35.

17. Schmidt HG, Moust JHC. Factors affecting smallgroup tutorial learning: a review of research. In: Evensen DH, Hmelo CE, editors. Problem-based learning: a research perspective on learning interactions. Mahwah, NJ: Lawrence Erlbaum; 2000. p. $19-52$.

18. Cate O ten, Durning S. Peer teaching in medical education: twelve reasons to move from theory to practice. Med Teach 2007;29:591-599.

19. Dandavino M, Snell L, Wiseman J. Why medical students should learn how to teach. Med Teach 2007; 29:558-565.

20. Weiss V, Needlman R. To teach is to learn twice: resident teachers learn more. Arch Pediatr Adolesc Med 1998;152:190-192.

\begin{abstract}
De auteurs:
Drs. Nick Wlazlo is arts-onderzoeker.*

Dr. Wim G. Peters is internist-hematoloog. *

Dr. Bjorn Winkens is statisticus en verbonden aan de Maastricht University, vakgroep Methodologie en Statistiek.

Prof. dr. Cees P. M. van der Vleuten is hoogleraar Onderwijskunde en verbonden aan de Maastricht University, vakgroep Onderwijsontwikkeling en -research.
\end{abstract}

* Beiden zijn werkzaam in het Catharina Ziekenhuis, vakgroep Interne Geneeskunde, Eindhoven.

\begin{abstract}
Correspondentieadres:
Nick Wlazlo, Catharina Ziekenhuis, vakgroep Interne Geneeskunde, postbus 1350, 5602 ZA Eindhoven.Tel.: 0402397220; fax: 0402397229; e-mail: nickwlazlo@gmail.com
\end{abstract}

Belangenconflict: geen gemeld

Financiële ondersteuning: geen gemeld

\section{Summary}

Introduction: The quality of near peer teaching has been shown to be similar to that of staff-led teaching during procedural skills training and PBL tutorials. It has not been investigated, however, if student-led formal teaching can be effective in clerkship settings. We conducted a randomised, cross over study to compare the quality and desirability of teacher led versus student led teaching during a clerkship in general internal medicine.

Methods: Twenty-six fourth year medical students received weekly one-hour sessions of formal teaching. They were randomised to one of two groups. Both groups were taught alternately by a student and an internist, but one group started with a student-led session and the other group with a teacher-led session. All students evaluated four sessions by completing, for each session, a questionnaire consisting of sixteen items to be rated on a ten-point scale. The mean item scores (overall evaluation) were compared using linear mixed models.

Results: A total of 92 completed questionnaires was obtained. The overall score was significantly higher for the student led (8.31) compared to the internist led (8.00; $p=0.004)$ sessions. This was due to higher scores on interaction, simulation, positive learning environment, overview and explanation of physiology.

Conclusions: Evaluation scores on theoretical teaching during a general internal medicine clerkship were higher on sessions led by a student than on sessions led by a haematologist. These results may be explained by cognitive and social congruence or by teaching skills having a stronger impact than content expertise. (Wlazlo N, Winkens B, Vleuten CPM van der, Peters WG. Near-peer teaching during a general internal medicine clerkship: a randomised cross-over trial. Netherlands Journal of Medical Education 2011;30(1-2):2-10) 